\title{
Research on the Application of Virtual Simulation Software in the Course of Building Environment
}

\begin{abstract}
Zhimei Wen ${ }^{1, *}$
\author{
${ }^{1}$ Shandong Huayu University of Technology \\ *Corresponding author. Email: 354187917@qq.com
}

ABSTRACT

Technical courses are the most important courses in the major of built environment, which play an important role in the whole architecture curriculum system. The course of built environment is a course content that needs to combine theoretical knowledge with practice. This course is highly specialized and covers a wide range of topics. Through the study of building environment professional, building environment for students to have a certain understanding and understanding, in the actual teaching process, many knowledge of students is difficult to understand, to specific content will appear some confusing problems, in order to improve the effect of classroom teaching, to solve the problems in the teaching process, through the way of combining theory and practice of using virtual simulation software to modern teaching information, improve the teaching effect.
\end{abstract}

Keywords: Virtual simulation, Built environment, Course, application

\section{THE PROBLEMS EXISTING IN THE COURSE TEACHING OF BUILT ENVIRONMENT SPECIALTY}

\subsection{The characteristics of virtual simulation software and classroom teaching are not outstanding}

In the building environment professional course teaching, many of the qualifications of the older teachers under the influence of the traditional exam-oriented education, teaching thoughts and thinking ideas can't keep pace with The Times, not timely to reform the teaching idea and teaching method, the multimedia teaching technology and some modern teaching means such as virtual simulation software is still not accepted, there is no reasonable use in the classroom teaching, still adopts the traditional way of lecturing in classroom teaching, so it is difficult to improve the students' learning motivation and learning enthusiasm. In addition, some teaching in the course of building environment professional course teaching, are simply through the lessons of the courseware with multimedia devices directly playback, coupled with blackboard writing classroom teaching and classroom teaching content, but still interact with the students have no atmosphere, the teacher can't accurately grasp and understanding students' psychological characteristics, influence the effect of classroom teaching ${ }^{[1]}$. The overall quality of teachers is not high, which directly affects the learning enthusiasm of students. The teaching methods and ideas adopted by teachers also further reduce the learning enthusiasm of students. In such a boring and rigid learning environment, it is difficult for students to improve their academic performance and ignore the dominant position of students, which makes it more difficult for the integration of teaching development and modern chemical technology.

\subsection{The teaching method is not flexible, the lack of exploration and discussion environment}

Under the background of modern virtual simulation software, many teachers all play on the building environment professional course teaching courseware as a means of teaching, according to their own years of experience in teaching arrangement of classroom teaching content, ignoring the students as main body status, lack of communication with the communication between students and, most of them are in the form of pictures and knowledge as the focus of the classroom teaching content, unable to communicate the subjectivity teaching content to students, even in many wonderful segment has not been deep mining. Many teachers only carry out some simple teaching activities through multimedia teaching technology in the daily teaching 
process, which eliminates the link of students' reading aloud, discussion and questions among classmates. In the process of teaching, excessive use of multimedia and virtual simulation software will make the teaching more formal, resulting in students cannot find the focus of learning, difficult to give play to the subjective initiative of students, affecting the autonomy of students in learning. Due to long time under the influence of traditional concepts of education, students are at in a sterile environment to learn, learning atmosphere is heavy, so that students can't fully to understand the knowledge, learning enthusiasm is not high, for teachers in all kinds of questions and no positive thinking seriously, therefore needs the teacher to in-depth exploration of teaching mode, so as to improve the students' learning motivation and learning enthusiasm.

\section{APPLICATION OF VIRTUAL SIMULATION SOFTWARE IN BUILDING ENVIRONMENT SPECIALTY COURSE}

\subsection{Build a comprehensive and systematic teaching resource library for the specialized courses of the built environment by using the Internet resources}

Through the Internet resources to build a comprehensive and rich curriculum teaching resources library of the built environment specialty. Cloud disk, as a professional tool for storing and transmitting Internet resources, is an inevitable outcome of the development of The Times under the background of Internet information sharing. With: large capacity, fast transmission, high security, stability and other characteristics, you can download and share the resources in the cloud disk at any time. In the course teaching of the major of built environment, teachers can summarize their teaching experience over the years, and then upload the learning resources to the Internet cloud plate by introducing and building a self-built database according to the specific learning situation of students, so that the learning resources can be shared with students at any time. The related teaching resources of the course of built environment include many aspects.

\subsection{Make full use of modern virtual simulation software to create situations for students}

Building environment professional course teaching pay more attention to cultivate students' emotion, especially for the building environment professional knowledge of teaching reading, more needs to be full of enthusiasm and interest, realize the building environment professional course knowledge contains huge energy, only guides the student to put himself into the building environment professional course teaching, so that students can better into the textbook knowledge learning, sublimate their emotions, to achieve the ideal effect, online teaching activities can make full use of the Internet platform of a large number of resources, through better form into context, the students experience the emotion of that time. The learning tasks of the course teaching of the major of built environment are somewhat abstract. If the teacher teaches the abstract concepts to the students in the form of language expression, the effect is far less obvious than better feedback to the students through the network resources $^{[2]}$.

\subsection{Make full use of virtual simulation software to stimulate students' interest in learning}

It is said that "interest is the best teacher for children". A famous American psychologist once said: learning requires learners to take the initiative to learn, students as the main body of learning, only to stimulate their interest in learning, so that they have power to learn knowledge to make students learn knowledge. In the teaching process of the built environment specialty course, it is necessary to create positive and favorable conditions for students to learn, and guide students to read and look more. In the course of online teaching of built environment major, it is necessary to make more use of the Internet platform to expand the learning channels of students. Let the students share the materials they have collected in the online class.

\subsection{The application of virtual simulation software teaching means in graphic design teaching classroom}

Teachers, as "disseminators of knowledge", are at the core of classroom teaching, and teachers are required to take the lead in class. In this way, the traditional teaching method basically has no interaction between teachers and students, and the classroom effect is relatively poor. If we simply rely on traditional teaching methods, we cannot make full use of all kinds of teaching resources prepared by teachers in classroom teaching. However, full use of modern network platform, the reasonable use of virtual simulation software of teaching software and teaching means, break the traditional teaching mode and various restrictions, fully using the virtual simulation software, lets the student can study anytime and anywhere, according to their own mastery of knowledge is learning repeatedly, can ask the teacher at any time, also can realize the communication and cooperation between classmates learning, teachers can also through the virtual simulation software teaching means more clearly grasp the learning situation of each student, make classroom teaching more efficient.

\subsection{Virtual simulation software applied in the specialized courses of the built environment}

Taking the design of gas pipeline as an example, it usually needs a computer program to complete it. By 
automatically connecting the system pressure, flow rate and pipeline interface dynamically, the optimization scheme is made for comparative optimization analysis in the design stage. At present, the most commonly used official website simulation software include Popeline Studio TGNET from ESI Company of the UK, SPS from Stoner Company of the US, and G-NET jointly developed by North China Design Institute of China Municipal Engineering and Beijing Saiyuan Technology Co., Ltd. TGNET and SPS dynamic simulation function is very powerful, and G-NET static simulation function is more prominent, which is more suitable for the teaching of built environment specialty. At present, GNET is still the main simulation software used ${ }^{[3]}$.

There are many commonly used computational fluid dynamics (CFD) software, among which FLUENT is the most mature and widely used. Fluent software has rich and advanced physical models and powerful postprocessing functions, such as laminar flow and turbulence, steady flow and unsteady flow, and nonviscous flow, etc. ${ }^{[4-5]}$. Teachers in class instance, the interpretation will be Fluent fluid simulation software commands and books of knowledge, the engineering practical problems in the form of homework after class to students, students are required to use Fluent software to simulate calculation, combined qualitative judgment on the rationality of the calculation results between teachers and students, help enterprise to solve practical engineering problems.

\section{ADHERE TO THE STUDENT- CENTERED EDUCATION CONCEPT, THE USE OF VIRTUAL SIMULATION SOFTWARE, STIMULATE STUDENTS' INTEREST IN LEARNING}

\subsection{The abstract problem is pictorial, the micro change trend, and the complex problem is modularized}

Abstract, complex and difficult physical models in fluid mechanics are used to simulate various related physical phenomena of fluid flow with FLUENT fluid simulation software, and converted into vivid graphics, images and animations. The micro air flow and molecular force are represented by trend line and change curve. The complex interaction problem is modularized and split, and the boundary is set and coupled to solve the problem respectively. The "three changes" of teaching content can help improve students' image-thinking ability, help students understand and master theoretical knowledge, improve the quality of classroom teaching, and stimulate students' interest and motivation in learning.

\subsection{Combine simulation test with real operation}

In addition to the normal class theory explanation and matching the experimental operation, using Fluent fluid simulation software of the virtual experiment platform for practice teaching, students may at any time to carry out the experimental study, simplify the experiment process, shorten the test cycle, can visually reveal test effect, and can reduce consumption of experiment and practice teaching process costs. It can also compare the collected data and experimental results with the actual experimental operation to improve students' ability to find, analyze and solve problems.

\subsection{Combine theoretical analysis with practical engineering problems}

In the teaching process, practical engineering problems are introduced. Fluent fluid simulation software is used to establish engineering models for analysis and solution, which not only improves students' ability to apply software, but also lays a foundation for students to combine scientific research theory with practical engineering.

\subsection{Develop ways for teachers and students to participate in practical engineering and scientific research work of enterprises.}

The advanced physical model and powerful postprocessing function of virtual simulation software are fully utilized. Class teacher in the interpretation of the instance, the virtual simulation software commands and books of knowledge, the engineering practical problems in the form of homework after class to students, students are required to use virtual simulation calculation software, combined qualitative judgment on the rationality of the calculation results between teachers and students, help enterprise to solve practical engineering problems.

\subsection{Continuous improvement and gradual promotion}

The successful application of the new teaching mode combining virtual simulation software and theoretical teaching will promote the teaching reform of the corresponding courses in our school. According to the teaching reform, the team will summarize and discuss to learn from each other's strengths and make up for each other's weaknesses, so as to popularize and apply it in other related majors in our school.

\section{CONCLUSION}

(1) To improve students' ability of independent study and scientific research work. Under the guidance of teachers, students determine a simulated topic related to their research direction in the early stage, and then carry 
out the course learning with the questions, so as to further clarify students' learning objectives and improve their learning initiative.

(2) Combine theoretical teaching with scientific research practice. In order to better complete the teaching task, teachers' scientific research work needs to develop to a deeper and higher level. Combining theory with practice and combining teaching content with practical engineering can not only enhance the attractiveness of the course, improve teachers' scientific research ability and teaching level, but also lay a foundation for students to learn the course and apply knowledge.

(3) Cultivate students' ability to solve practical engineering problems. Students can use FLUENT software to simulate the practical engineering problems proposed by teachers, and make qualitative judgment on the rationality of the calculation results.

(4) Improve the effective utilization of existing teaching resources. Highlight the advantages of schoolenterprise cooperation in running schools, carry out special training for enterprises, solve practical engineering problems for enterprises, improve social service ability, so that students can not only be exposed to practical engineering in class, but also participate in the research of practical scientific research projects after class, so as to truly apply what they have learned.

(5) Using virtual simulation software for dezhou city building, heating, ventilation, solar energy companies such as analysis of the feasibility of the products, looking for better construction process, the optimal installation, through solving practical problems, improve teachers' team using theoretical knowledge solution actual problem ability, is conducive to the growth of teachers, beneficial to the cultivation of the students, for the enterprise scientific support to design, reduce cost and increase economic benefits.

(6) To carry out virtual simulation software training for enterprises in need, improve the software simulation ability of enterprise technicians, so that employees can learn new knowledge and apply new skills to improve their personal performance and boost the development of enterprises.

(7) By extending the virtual simulation software to environmental fluid mechanics and physical - chemical fluid dynamics, the principle of wind effects on buildings, study on biomass, natural gas and other clean energy air flow combustion effects, in order to further the virtual simulation software extended to other disciplines of our hospital, the school professional support and service.

With the development of science and technology, virtual simulation software will become the direction of teaching reform and development in the future, but also the inevitable requirement of modern education. How to reasonably apply virtual simulation teaching technology to the courses of built environment specialty, it requires teachers to effectively apply and reasonably realize the health reform and development of education in China.

\section{ACKNOWLEDGMENTS}

Foundation Project: Research achievement of "Application of Virtual Simulation Software in the Course of Building Environment" (2019JG21), Shandong Huayu University of Technology, 2019 School-based Education and Teaching Reform Research Project.

\section{REFERENCES}

[1] XIONG Jianping. Application of Virtual Simulation Software Based on Proteus in Higher Vocational Electronic Courses [J]. Education Modernization, 2017, 4 (37) : 160-161.

[2] Wang Caiping. Research on the Application of Proteus Virtual Simulation Software in Electronic Information Courses in Secondary Vocational Colleges [D]. Hebei Normal University, 2017.

[3] Yuan Fanhua. Application of Virtual Simulation Software in Computer Network Technology Course [J]. Computer Knowledge and Technology, 2011, 7 (20) : 4926-4927.

[4] XIE Cuili, NI Lingying. Discussion on the Introduction of CFD Teaching in the Undergraduate Course of Engineering Fluid Mechanics [J]. Mechanics in Engineering, 2013, 35 (3) : 91-93.

[5] Zhou Yang, Li Mei. Practice Research on Teaching Reform of Fluent Software Introduced into Engineering Fluid Mechanics [J]. Guangdong Chemical Industry, 2017, 44 (3) : 166-177. 